\title{
Clinical Profile and Outcome of Acute Encephalitis Syndrome in Dhulikhel Hospital of Nepal
}

\author{
Dongol S', Shrestha S², Shrestha N³ , Adhikari J4 \\ ${ }^{1}$ Dr. Shrijana Dongol, MBBS, MD, Assistant Professor, ${ }^{2}$ Dr. Shreema Shrestha, MBBS, MD, Assistant Professor, ${ }^{3}$ Dr. Narayan \\ Shrestha, MBBS, MD, Lecturer, ${ }^{4}$ Dr. J Adhikari, MBBS, Intern. All from the Department of Paediatrics, Kathmandu University, \\ School of Medical Sciences ( KUSMS), Dhulikhel, Kavre, Nepal.
}

Address for correspondence: Dr. Srijana Dongol, E-mail: docsrijana@yahoo.com

\begin{abstract}
Introduction: Acute encephalitis syndrome (AES) is a constellation of clinical signs and or symptoms i.e. acute fever with acute change in mental status. AES may be present as encephalitis, meningoencephalitis or meningitis. It can be associated with severe complication, including impaired consciousness, seizure, limb paresis or death. Materials and Methods: Study consisted of retrospective analysis of hospital records of children up to 16 years of age admitted with diagnosis of AES in the department of Paediatrics Dhulikhel Hospital, Kathmandu University Teaching Hospital, Dhulikhel Kavre from January 2010 to December 2011. Results: During the two years (January 2010 to December 2011), 47 patients of AES were admitted. Among the admitted cases there were 34 male and 13 female patients. Meningitis cases were 29, encephalitis cases were 14 and 4 meningoencephalitis cases. Among the meningitis cases, viral meningitis accounted for 12, bacterial meningitis accounted for 15 and 1 tubercular meningitis.One was eosinopilic meningitis in which the causative organism was found to be fasciolosis by ELISA. Viral encephalitis was found to be the most common cause of encephalitis. Sensorineural hearing loss was seen in 3 cases, subdural effusion in 1 and hydrocephalus in 1. One patient had intracranial hemorrhage with hemiparesis as a complication of eosinophilic meningitis. Conclusion: Acute encephalitis syndrome is one of the most common causes of PICU admission in Dhulikhel hospital. Bacterial meningitis was common among the acute encephalitis syndrome followed by viral meningitis. One case of eosinophilic meningitis with intracranical hemorrhage and hemiparesis was found. Sensorineural hearing loss was found to be commonest complication.
\end{abstract}

Key words: Acute encephalitis syndrome (AES), ELISA, Encephalitis, Meningitis

\section{Introduction}

$A_{\text {ot }}^{\text {cat }}$ cute encephalitis syndrome (AES) is a constellation of clinical signs and or symptoms i.e. acute fever with acute change in mental status and or new onset of seizures ${ }^{1}$. AES may be present as encephalitis, meningoencephalitis or meningitis and may be caused by virus, bacteria, mycobacterial, rickettsia and in rare cases- toxoplasma ${ }^{2}$. Viruses are regarded as the most important cause of the acute encephalitis syndrome worldwide. However, the syndrome can be associated with a range of pathogens, including bacterial or parasitic infections. Cerebral malaria and non infectious causes of encephalopathy are required to be excluded while considering AES. In the population based studies, the incidence range between 3.5-7.4 cases per 100,000 patient per year ${ }^{3}$. Acute encephalitis syndrome can be associated with severe complications, including impaired consciousness, seizure, limb paresis, or death ${ }^{4}$.
Three-quarters of meningitis cases are believed to occur before 15 years of age. Three organisms (Streptococcus pneumonia, Neisseria meningitides and Haemophilus influenza type B) account for $80 \%$ of cases. $H$. influenza has declined very significantly following routine immunization in infancy ${ }^{5}$. Tubercular meningitis (TBM) usually occurs within 12 months of primary infection. Most frequently TBM occurs in those under five years of age. Focal neurological deficit, seizure, or severely depressed conscious level may occur. In 40-90\% cases of TBM, primary focus can be seen in chest X-ray 5 . Lumber puncture and cerebral spinal fluid (CSF) analysis is still considered as the gold standard tool for diagnosis of acute encephalitis syndrome. As part of efforts to control $\mathrm{JE}$, the World Health Organization (WHO) is providing a set of standard of JE surveillance, which requires the identification of patients with AES. Confirmation of diagnosis of JE is usually done by JE specific titer of IgM 
antibodies in serum and or in CSF during acute illness of suspected AES cases ${ }^{6}$.

There have been several publications relating admission, clinical parameters to outcome among JE cases, and identification of poor prognostic indicators has helped focus attention on treatable complications of infection ${ }^{7-9}$. However, relatively little work has been done regarding clinical profile, outcome and prognostic feature among the non JE (AES) patients. We therefore decided to investigate for the causes, diagnoses and outcomes of non JE (AES) cases.

\section{Materials and Methods}

This is a hospital-based, retrospective study, done in the department of Paediatrics at Kathmandu University Teaching Hospital, Dhulikhel, Kavre. Children up to 16 years were included in this study and study period was from January 2010 to December 2011. Data was extracted from admission and discharge books of Paediatric Intensive Care Unit (PICU) and the paediatric ward, and from inpatient record files. Case records of these patients were analyzed in detail and data recorded from history, examination, investigation and outcome. Surveillance of JE is being done by WHO in endemic areas through detection of JE Ig-M antibodies in acute stage of AES patients in CSF sample. CSF samples of all clinical AES cases from our institution are routinely being sent to WHO Immunization Preventable Disease (WHOIPD) field office.

The acquired data for all AES patients was initially validated, coded, and entered in SPSS Statistics software version 17.0 was used for analysis.

Inclusion criteria: All children from 1 month to 16 years admitted in Paediatric Department with symptoms of meningitis, meningoencephalitis and encephalitis.

Exclusion Criteria:Patientswith AESlike presentations but with clinically and investigation proven malaria and other non-infectious encephalopathy

\section{Results}

There were 47 cases of AES which fulfilled the inclusion criteria. Age and sex distribution of these cases are shown in Table 1. There were 8 cases less than 1 years, 28 cases were between 1-10 years and 11 cases were between 10-15 years respectively. AES cases among the male population (72.34\%) were almost 3 times more common than among females (27.65\%).

Clinical profile of these patients are shown in Table 2. Fever was the most common symptom and it was found in $100 \%$ of cases. Other symptoms commonly associated with this disease were vomiting (51\%), seizure (44\%), altered sensorium (21\%) and headache in (21\%). According to the CSF analysis 16(34\%) were considered to have AES of bacterial etiology, including 1 (2.12\%) with tubercular etiology, 18(38.29\%) were considered to have viral etiology, only $1(2.1 \%)$ had eosinophilic (parasitic) etiology and $23.40 \%$ had normal CSF analysis.

Table 2: Profile of AES cases $(n=47)$

\begin{tabular}{|l|r|}
\hline \multicolumn{1}{|c|}{ Features } & Number (\%) \\
\hline Fever & $47(100 \%)$ \\
Vomiting & $24(51.06 \%)$ \\
seizure & $21(44.68 \%)$ \\
Headach & $10(21.27 \%)$ \\
Altered sensorium & $10(21.27 \%)$ \\
LOC & $2(4.25 \%)$ \\
GCS $<$ & $7(14.86 \%)$ \\
Sign of meningeal irritation & $26(55.31 \%)$ \\
Neurological deficit & $4(8.51 \%)$ \\
& \\
CSF(cell count,biochemistry,gram & $16(34.04 \%)$ \\
stain or C/S) & $18(38.29 \%$ \\
Suggestive of bacterial meningitis & $1(2.12 \%)$ \\
Suggestive of viral meningitis/ & $1(2.12 \%)$ \\
encephalitis & $12(23.40 \%)$ \\
Suggestive of eosinophilic meningitis & \\
Suggestive of TB meningitis & \\
Normal CSF & \\
\hline
\end{tabular}

Meningitis, encephalitis and meningoencephalitis cases were 29, 14 and 4 respectively. Table 3 shows more details about the causative organisms. Among the meningitis cases, bacterial meningitis was the most commonly observed and among the encephalitis and meningoencephalitis cases, viral etiology was the most commonly observed. In the case of eosinophilic meningitis, the causative organism of which was

Table 1: Showing the distribution of AES according to age and sex.

\begin{tabular}{|c|c|c|c|c|c|c|}
\hline Age & Male & $\%$ & Female & $\%$ & Total & $\%$ \\
\hline$<1$ years & 6 & 12.76 & 2 & 4.25 & 8 & 17.01 \\
\hline 1 -10 years & 20 & 42.55 & 8 & 17.02 & 28 & 59.57 \\
\hline $10-16$ years & 8 & 17.02 & 3 & 6.38 & 11 & 23.40 \\
\hline Grand Total & 34 & 72.34 & 13 & 27.65 & 47 & 100 \\
\hline
\end{tabular}


Fasciolosis by ELISA. JE was observed in only one case as per documented reports received from WHO (IPD).

Table 3: Distribution of total cases of AES according to causative agents $(n=47)$

\begin{tabular}{|l|r|}
\hline \multicolumn{1}{|c|}{ Diagnosis } & Number(\%) \\
\hline Bacterial & $17(36 \%)$ \\
Bacterial meningitis & 15 \\
Bacterial encephalitis & 1 \\
Tubercular meningitis & 1 \\
& \\
Viral & $29(61 \%)$ \\
Unknown viral etiology & 28 \\
Viral meningitis & 12 \\
Viral encephalitis & 12 \\
Viral meningoencephalitis & 4 \\
Known viral etiology & 1 \\
Japanese encephalitis & $1(2.1 \%)$ \\
Parasitic( Eosinophilic ) Meningitis & \\
\hline
\end{tabular}

There were a total of 47 AES cases diagnosed. During the hospital stay only one case expired. Four cases left against medical advice, so follow up was not possible in these cases. Among the other 35 cases that stayed in the hospital until discharge and also came for follow up, 7 cases developed complications.

Table 4 further elaborates on the complications in relation to the causative organisms. Sensorineural hearing loss was the most commonly seen complication in bacterial meningitis cases. Other complications were subdural effusion and hydrocephalus. Intracranical haemorrhage and hemiplagia were the complications seen in eosinophilic meningitis. There was only one case of J.E who was discharged without any neurological sequel.

\section{Discussion}

Acute encephalitis syndrome is one of the most common causes of PICU admission in the Dhulikhel Hospital. This study shows that there were 34 (72.34\%) male in comparison to $13(27.65 \%)$ female. Rayamajhi in their study found $69 \%$ male and $31 \%$ female which is about the same as in present study ${ }^{4}$. Similarly another study done in India by Potula $\mathrm{R}$ et $\mathrm{al}^{10}$ and study done in Bharatpur, Nepal by Y.R Khinchi et al ${ }^{11}$ have also showed males to be affected more than females. Fiftynine percent patients in this study were one to ten years. Seventy six percent patients in this study were under 10 years of age. Raghava Potula in his study found $71.2 \%$ patients less than ten years ${ }^{10}$. Shrestha SR in his study as well found $75 \%$ patients less than ten years ${ }^{12}$. These data are similar to this present study. The number of children less than 10 years was more common in our study as compared to one done by Ajit et $\mathrm{al}^{4}$.

In the present study, fever was the most common symptom as it was found in $100 \%$ of cases. Other symptoms commonly seen were vomiting (51\%), seizure(44\%), and altered sensorium (18.75\%). Neeru Gupta et $\mathrm{al}^{13}$ found fever in $100 \%$ cases and convulsion in $51.71 \%$ of cases. The findings of our study are similar with findings of other studies. A Glasgow coma scale (GCS) rating $<8$ and meningeal irritation signs were observed in $14 \%$ and $55 \%$. Khinchi et al ${ }^{11}$ in his study found GCS $<8$ and meningeal irritation signs in $29.5 \%$ and $49.1 \%$ respectively which is similar to our study.

Table 4: Complication of AES cases according to different etiology $(n=35)$

\begin{tabular}{|l|c|c|c|c|c|}
\hline \multicolumn{1}{|c|}{ Diagnosis } & $\begin{array}{c}\text { Sensorineural } \\
\text { hearing loss }\end{array}$ & Hemiparesis & Hydrocephalus & Subdural effusion & $\begin{array}{c}\text { Intracranial } \\
\text { haemorrhage }\end{array}$ \\
\hline Bacterial meningitis & $2(4.2 \%)$ & - & $1(2.1 \%)$ & $1(2.1 \%)$ & - \\
Tubercular & - & - & - & - & $1(2.1 \%)$ \\
meningitis & - & $1(2.1 \%)$ & - & - & - \\
$\begin{array}{l}\text { Eosinophilic } \\
\text { meningitis }\end{array}$ & - & - & - & - & - \\
Viral meningitis & - & - & - & & - \\
Bacterial(Enteric) \\
encephalitis
\end{tabular}


CSF analysis was done in all cases of AES. According to CSF analysis report sixteen patient,(16/47;34\%) were considered to have AES of suspected bacterial etiology. Eighteen patients (18/47 ie 38.29\%) were considered to have viral etiology and only one had eosinophilic (parasitic) etiology and twelve (12/47 ie $25.53 \%$ ) had normal CSF analysis.

$\mathrm{JE}$ is the single largest cause of viral encephalitis in the world ${ }^{14}$. Epidemics of JE are documented in Southeast Asia and throughout most of the Indian subcontinent. To monitor $\mathrm{JE}, \mathrm{WHO}$ has given clinical case definition of AES so that these cases are subjected for confirmative diagnosis by Ig $\mathrm{M}$ captured ELISA in blood and or CSF. All patients that met the clinical case definition AES, CSF sample was sent for confirmation of JE. Though Kavre district is known as epidemic area, there is only 1 confirmed case of J.E. In the present study the incidence of J.E was only $2.1 \%$.Among all the 47 cases of CSF analysis, $37 \%$ of CSF analysis result suggestive of bacterial origin while $38 \%$ suggestive of viral origin. Similar result was also observed in another study done by Khinchi Y.R et $\mathrm{al}^{11}$ in which $40.9 \%$ of CSF analysis was suggestive of bacterial origin and $36 \%$ of viral origin. Among all the viral encephalitis cases only $1(7 \%)$ confirm case of Japanese encephalitis was found. This finding was contrast to the finding of same study done by Khinchi Y.R et $\mathrm{al}^{11}$ in which the incidence of JE was almost $50 \%$ among all viral encephalitis. Eosinophilic meningitis is a rare cause of meningitis. In this study there was only one case of eosinophilic meningitis. In this case the causative organism was found to be Fasciolosis by ELISA in blood. Among all 47 studied population, 4 left against medical advice, so their outcome was not known. One patient expired during his hospital stay. Seven patients were discharged with complications.

Among the AES patients the only patient who expired was diagnosed as a case of viral meningoencephalitis.

There was only one case of JE confirmed by JE IgM CSF, who was discharged with full recovery without any neurological sequel. AES of bacterial origin developed most severe complication like neurological deficit, hydrocephalus and subdural effusion. Intracranial hemorrhage and right sided hemiparesis were seen as a complication of eosinophilic meningitis. Eosinophilic meningitis by Fasciolosis with complication like $\mathrm{ICH}$ is extremely rare. Ying $M$ et al in 2007 also described 2 similar cases of eosinophilic meningitis with $\mathrm{ICH}^{15}$.

As there was only one JE confirmed, the author did not deem it logical to comment and compare this case with other studies. In another study, done by Bista YB and Shrestha JM in the year 2005 shown the case fatality rate ranges from $9.8 \%$ to $46.3 \%$ from the year 1978 to $2003^{16}$. Among all complications, sensorineural hearing loss was seen in $6.4 \%$ and hemiparesis was seen in $2.1 \%$. Baraffet et al did a meta analysis of bacterial meningitis published from 1953 to $1993^{17}$. In that study, the most common complications were deafness in $10.5 \%$ and paresis in $3.5 \%$, which is quite similar with our study.

\section{Conclusion}

Meningoencephalitis syndrome among the male population was almost three times more commonly seen than female population. It is seen mostly among the school going children. Among the meningitis bacterial etiology was commonly observed and among the encephalitis and meningoencephalitis, viral etiology was commonly observed. Eosinophilic meningitis was also found. Fever, vomiting, headache and altered sensorium were the commonest clinical presentations. Sensorineural hearing loss was a common complication followed by subdural effusion and hydrocephalus. Intracranial hemorrhage and hemiparesis was seen as the complication of eosinophilic meningitis. Seventyfour percent $74.46 \%$ patients with AES were discharged without any neurological sequel.

\section{Acknowledgements}

We would like to thank Dr. Sagar Shakya, WHO IPD field office Kavre for his help in JE surveillance and providing all result of CSF anlaysis.

\section{Funding: None \\ Conflict of Interest: Nil \\ Permission from IRB: Yes}

\section{References}

1. Soloman T, Thao TT, Lewthwaite P, Ooi MH, Kneen R, Dung NM, White N:A cohort study to assess the new WHO Japanese encephalitis surveillance standards. Bull World Health Organ 2008,86(3):178-186.

2. Mishra U K, Tan CT, Jayanti K. Seizures in encephalitis. Neurology Asia;2008:1-13.

3. Granerod J, Crawcraft NS: The epidermiology of acute encephalitis. Neuropsychol Rehabil 2007,17(45):406-428.

4. Rayamajhi A, Singh R, Prasad R, Khanal B, Singh S: study of Japanese encephalitis and other viral encephalitis in Nepali children. Pediatr Int 2007,49(6):978-984.

5. Bruder Stapleton F, Tasker R, Mc Clure J.R.Meningitis Oxford American handbook of Pediatrics. $1^{\text {st }}$ ed. 2011.p.835-839. 
6. Fidan J, Emsley $\mathrm{H}$, Fisher $\mathrm{M}$ et al. The incidence of acute encephalitis syndrome in western industria lizedcountries:Virologyjournal2008,5: 134(hltp:// www virology j.com/content/5/1/134;assessed on 12.2.1010).

7. Saomon T, Dung NM, Kneen R, Gainsborough M, Vaughn DW, Khanti VT: Japanese encephalitis.J Neuro Neurosurg Psychiatry 2000,68(4):405-415.

8. Libraty DH, Nisalak A, Endy TP, Suntayakorn S, Vaughn DW, Innis BL:Clinical and immunological risk factors for severe disease in Japanese encephalitis. Trans R Soc Trop Med Hyg 2002.96 (2):177-178.

9. Kumar R, Mathur A, Sharma S, Chakraborty S, Chaturvedi UC: Clinical feature and prognostic indicator of Japanese encephalitis in children in Lucknow (India). Indian J Med Res.1990,91:321-327.

10. Potula $R$, Badrinath $S$ et al.Japanese Encechalitis in and around Pondicherry, South India: A Clinical Appraisal and Prognostic Indicator of the outcome. J. Trop Pediatrics 2003:49:49-53.

11. Khinchi Y.R, Kumar A, Yadav S: Study of acute encephalitis syndrome in children. Journal of College of Medical Science-Nepal, 2010,6(1):7-13.
12. Shrestha SR, Awale P, Neupane S, Adhikari N, Yadav BK: Japenese Encephalitis in children admitted at Patan Hospital. J Nepal Paediatri.Soc2008,29(1):1721.

13. Gupta N, Chatterjee K, Karmakar S, Jain SK, Venkatesh S, Lal S, Bellary, India achieves negligible case fatality due to Japanese encephalitis despite no vaccination; an outbreak investigation in 2004.,Ind J Pediatr 2008;75:31-37.

14. Kumar R, Tripathi $P$, Singh $S$ et al. Clinical features in children hospitalized during the 2005 epidemic of Japanese Encephalitis in Uttar Pradesh,India. Clinical infectious disease, 2006;43:123-31.

15. Ying $M$, Xiaosu $H$, Wang B. Trans R Soc Trop Med Hyg. 2007 Oct;101(10):1051-2.

16. Bista M B, Shrestha J M. Epidermiological situation of Japanese Encephalitis in Nepal. J Nep. Med Assoc2005;44(158):51-6.

17. Baraff LJ, Lee SI, Schriger D. Outcome of bacterial meningitis in children:a meta analysis. Pediatr Infect Dis J 1993;12(5):389-94.

\section{How to cite this article?}

Dongol S, Shrestha S, Shrestha N, Adhikari J. Clinical Profile and Outcome of Acute Encephalitis Syndrome in Dhulikhel Hospital of Nepal. J Nepal Paediatr Soc 2012;32(3):201-205. 